\title{
Personal reflections: What happens when disaster hits?
}

\section{Lynne Brigg and Molly Heisenfelt Roark}

Lynne Briggs is an Associate Professor in the School of Human Services and Social Work at Queensland's Griffith University. She also holds an adjunct position in the Department of Sociology, Gender and Social Work at Otago University. Molly Heisenfelt Roark lives in Minnesota in the US, where she is a school social worker at the Community of Peace Academy, and also a Licensed Independent Clinical Social Worker at Nystrom and Associates.

\section{Abstract}

This article is a reflection by two social workers who were involved both personally and professionally in a community in stress in the aftermath of the Christchurch earthquakes. As such we worked as volunteers offering counselling to people in need through the Canterbury Charity Hospital. While one of us lived through the earthquakes and the other was only a part of the quake-stricken community for a short period of time, both were witness to the appreciation, resilience, and courage paramount in clients; the emotional accounts of survival and loss; and Cantabrians going through the ongoing aftershocks that have relentlessly pounded our city over the past two and half years.

\section{Introduction}

Four major earthquakes have hit Christchurch. The first to jolt Christchurch awake was a magnitude 7.1 earthquake, which struck at 4:35am on 4 September 2010, causing widespread damage and several power outages, particularly in the city (Radio New Zealand, 2010).

Few New Zealanders will ever forget February 22, 2011. At 12.51pm, the second earthquake devastated Christchurch, New Zealand's Garden City, killing more than 180 people, destroying many homes and heritage buildings, and affecting tens of thousands of citizens. This earthquake caused widespread damage across Christchurch, especially in the central city and eastern suburbs, with damage exacerbated by buildings and infrastructure already weakened by the 4 September 2010 earthquake and its aftershocks. Nationals from more than 20 other countries were among the victims (The Press, 2012).

On 13 June 2011 a third, magnitude 5.6 quake struck Canterbury at $1 \mathrm{pm}$. This earthquake sent people scrambling for cover. It was followed at $2.20 \mathrm{pm}$ by a more powerful magnitude 6.3 earthquake. At least 40 people were injured, two seriously, and at least 10 people were taken to Christchurch Hospital with injuries due to falling building material. This was followed on 23 December 2011 by yet another swarm of earthquakes including a magnitude 6 and three more, at or above, magnitude 5 .

These earthquakes and the ongoing aftershocks have had considerable negative effects 
for many Cantabrians as, like the land, their plans and dreams for the future have crumbled around them.

\section{The before and after picture}

Many accounts found in the literature refer to the awesome power of nature in regard to the devastating effects of natural disaster and the limited capacity of humans to control it (Melton \& Sianko, 2010, p. 536). We also know from our own personal experience of having lived through the earthquakes, and from listening to the stories from our clients, that when natural disaster hits it does so with varying degrees of chaos and destruction. Retrospectively, one can see that the full impact of the Christchurch earthquakes depended to a certain extent on where you lived in the city. For example, physiological needs in the eastern suburbs and city centre were of utmost importance in the aftermath of the earthquakes, as shops unable to open made food scarce, the water was contaminated, houses were destroyed, sleep was elusive and sanitation systems were compromised. In addition to emotional challenges created by anxiety and uncertainty, people also had to contend with physical challenges including respiratory problems created by the destruction and liquefaction that occurred. These conditions were in stark contrast to other areas that were less affected.

Talking to people it was easy to see that any semblance of life in balance was destroyed. People were very aware of what they had lost, they knew the 'before' and the 'after' effects of the earthquake. The whole world had not stopped - only their world had, and in their vulnerability and fear they waited, wondering when and if life would ever return to normal. On the other side of the city people were able to basically continue living their normal everyday life (albeit with difficulty once they hit the streets). They were not indifferent and when the news got out many opened their homes and offered assistance to people in need, but overall their experience was different, as was their understanding of the dislocation that had occurred for the people living in the more affected areas of the city.

One of the most vivid recollections Lynne had, which clearly illustrates this, happened after driving from the east side of the city to a friend's place in the west. Due to the conditions of the roads a journey that would normally take 40 minutes took nearly two hours. While parking outside her friend's home she noticed a sprinkler going in the garden next door and in the driveway a man was using a hose to wash his car. This was somewhat bewildering because in the east there was no water for showers or washing, no flushing toilets, the Army were issuing bottles of drinking water and it was rationed - the assumption here was that the whole city was on water restrictions. While she stood there wondering at this, a City Care car pulled up and the worker got out and addressed the man. He told him if he had water to spare he should bottle it and take it to the other side of the city where people had none.

Reflecting on this incident later, Lynne concluded that it wasn't that this man didn't care - he just didn't know what other people were experiencing. It also reflects what happens when an event is no longer headline news, that is, people not immediately affected tend to think things are back to normal and the crisis is over. In reality that is not so, as the earthquakes and the ongoing aftershocks have had negative effects for a great many Cantabrians; their lives have been shattered and while many people are relatively resilient, others may need assistance to adapt to their changed circumstances. 


\section{Resilience}

Resilience and positive adaptation are interesting and overlapping concepts that have been bandied about and defined by many. For some resilience means having the skills, attributes and abilities to adapt to hardships, difficulties and challenges (Alvord \& Grados, 2005). Others (Patterson, 2002), see it more simply, and perceive it as being able to do well despite adversity. Thus, in the main, resilience is frequently defined as positive adaptation to adverse situations.

There is, however, variation in the use of the term resilience and perhaps, as Strongman (2012) suggests, in Christchurch the concept has been overused in an attempt to contain the devastating effects upon the people and the physical city. She argues the case well, and suggests that perhaps the use of the word is a sleight-of-hand that conceals more than it reveals. Strongman notes the visionary new draft Central City Plan uses words like 'resilient' or 'resilience' 36 times in 154 pages. She wonders how our ruined city will be rebuilt with a foundation of resilience? That is, the new buildings that populate it will be resilient to the violent seismic activity we have now come to expect, and social resilience and the strength of communities will be considered in the construction of urban public space and in zoning decisions.

More significantly, as Strongman (2012) observes, the people of Canterbury, who have experienced a sequence of more than 2,500 earthquakes of magnitude 3 and above (including the three major events that levelled the CBD and rendered entire neighbourhoods uninhabitable) are often said by national and local commentators to be extremely resilient.

Strongman has a point when saying this gives a false picture as to how the people of Canterbury are really faring. Looking at what has happened to people over the two years of ongoing earthquakes, we have talked with people who have lost their homes and worldly possessions, and in some cases family members and friends. Furthermore, many of these people have had no choice but to rent in other areas of the city with the result being that often the most vulnerable have been forced to leave the communities that have provided them with social supports. Thus, by describing the residents of the city collectively as 'resilient' does effectively diminish the real-life effects of the disaster on the lives of a large proportion of the population. If resilience is a measure of the amount of strain that can be absorbed before people reach the limit of their endurance, then in many cases the people of Christchurch are there and, in reality, are as damaged as the city.

While this may appear a somewhat subjective position to take, Strongman does make some very valid points and it is true the Christchurch we knew has gone forever. However, as professionals working with people trying to cope, what we do know is that the ability to overcome and persevere is paramount in healing and recovery and as social workers we hold strong to that belief.

This was evidenced in our work in the Charity Hospital. For many Cantabrians being able to seek help allowed them to receive support that assisted them in achieving a degree of balance in their lives. Additionally, giving early psychological support to a population under stress can avoid stress reactions becoming chronic, as well as allowing for people experiencing more extreme reactions to be identified and referred on for further assistance if required. 


\section{The Canterbury Charity Hospital}

Following the February earthquake, the Canterbury Charity Hospital expanded its facility to include a brief intervention counselling service to people in need. Generally, this service consisted of an assessment with one or two follow-up sessions. If longer intervention was needed then clients were referred on to appropriate services for further assessment and follow-up.

Looking back, we can see that the response by the Charity Hospital came at a critical time and a great number of the people attending for counselling were supported by the relationships that were promoted and fostered by the volunteer practitioners who gave their time for the benefit of the community. As Norris, Friedman and Watson (2002, p. 248) argue, for people providing mental health services in disaster counselling a primary role is to enable clients to gain skills that will enable them to rise above adversity. At the Charity Hospital the clients we worked with were in varying stages of coping, thus the main goal was to find ways to assist them manage on a day-to-day basis with the turmoil that had been their lives since 4 September, 2010.

Molly came to New Zealand 10 months after the first earthquake had occurred and through the Charity Hospital provided therapeutic support to people aged between 6 and 78 years. During the month she was there she undertook 81 therapy sessions with 49 females and seven males, and 25 returned for follow-up visits. While the clients presented with combinations of worries, anxiety, stress and sleep disturbances related to the earthquakes, when looking back Molly found that in general the people had forgotten the things they had previously enjoyed doing. They were just trying to make it through each day, wondering when the next shake was going to happen, assessing their safety and creating plans for their survival. Their hobbies, the things they were good at, and the things that once brought them light and joy were buried somewhere deep within them under layers of fear and uncertainty.

For Molly, a major therapeutic task had been assisting clients to reconnect with their spirit and the things that could help them uncover their souls in order to find their essence again. That is, to find hope, to build on strengths and to cultivate confidence.

It was only later, when we had both left the city and were able to reflect about our time spent working in the Charity Hospital that Molly realised she was doing what Norris et al. (2002, p. 248) suggests, that is to focus on each client's unique strengths, gifts and abilities in order to ensure that the emphasis of the intervention is to draw upon and build client self-sufficiency. Using this process, the clients that she saw had often demonstrated a tremendous ability to overcome the challenges that the earthquakes had presented.

We both also wondered about the impact of being in a helping role if you are also a survivor of the same disaster. There are tensions in the literature over this issue with much of the debate centring on the importance of professionals needing support for themselves as well as ensuring they do not try to 'do too much' for others (Yoder, 2008, p. 30). This is an important issue, as professionals can become overwhelmed with the intensity of the problems which can lead to clouded thinking, making consultation with others essential for crisis intervention. 
Benveniste (2006, p. 2) proposes one way to lessen the impact is to offer disaster counselling from a site where interdisciplinary interaction between colleagues is possible. This provides an environment where practitioners have the opportunity for mutual supervision and consultation with other professionals. Working at the Charity Hospital certainly provided a safe forum for this to happen, as doctors and other professionals were available for consultation at all times.

\section{The response of the social work profession to natural disasters}

The earthquakes have also made us think hard about our core social work curriculum, and to consider how we prepare the profession to respond to natural disasters such as the Christchurch earthquakes. Mathbor (2007) defined social work as '... a discipline that originated from grassroots movements that continuously deals with unexpected shocks and utilizes people's strengths' (p366). Using Mathbor's definition, we know that our role is to assist people cope with unlikely events by building on their positive attributes.

In hindsight, the Charity Hospital recruited counsellors from the Canterbury community, many of which were social workers, to voluntarily provide their professional skills to others in the time of crisis. As such this provided a space with appropriate protocols in place for social workers, alongside others, in which to work.

Social workers were also engaged in other services as well, for example, some went with other disciplines and carried out assessments in people's homes. Others worked in the Crisis Centres set up by the Canterbury District Health Board, while still more worked through community agencies. Regardless of the risk to their own personal safety, social workers also came from other parts of the country and Australia to offer professional help to a stressed community. Thus, collectively, as a profession, social workers offered their assistance and support in a variety of ways to the people of Canterbury.

Furthermore, while acknowledging that there is always a need for more specialised interventions, a key aspect was the offering support to people in need, as this appeared to be one of the most effective ways to provide assistance to those most affected by the disaster. This factor was evidenced in Mukhier's study (2006) where providing psychosocial support (which in the past had been considered as soft and not tangible in terms of assistance to those affected by the devastating 2003 earthquake that struck Iran killing 29,878 and injuring another 226,280) was seen as a key component of an effective emergency response.

Looking at the future of Christchurch post-earthquake and into the rebuilding phase, individual, family and community-based supports are critical and are all approaches in which social workers are skilled. While this may be so, as Mathbor (2007, p. 367) points out when considering how prepared the social work profession is for natural disasters, there is an urgent need for us to be more proactive, as opposed to reactive and more professionally prepared to navigate disaster. This makes education and training of utmost importance as natural disasters are a more common phenomenon than generally anticipated which require a curriculum that ensures graduate social workers have the skills to effectively work in disaster situations.

Finally, as Melton and Sianko (2010, p. 544) highlight, there is a paucity of sufficient research about how to avoid or reduce the adverse effects of disaster and in doing so these 
authors advocate for a major, long-term scientific initiative that will provide a sound knowledge base for implementing comprehensive disaster management. Thus, as a profession we are in a good position to provide leadership and direction in undertaking such an endeavour.

\section{Conclusion}

In looking back on what happened it is apparent that multidisciplinary cooperation is a key challenge in post-disaster work as the establishment of effective links between the different disciplines is required for both ideological and educational adaptations from professional groups. This can be achieved through a process of continuous dialogue, advocacy and learning between the professionals and the local community. As Henley, Marshall and Vetter (2011, p. 138) claim, it is only through such dialogue and advocacy that service providers and researchers will be able to provide the most effective 'best' practices that are culturally responsive and acceptable to all concerned.

The concept of positive adaptation, despite adversity, has existed practically since humans began reflecting on their own behaviour (Fleming \& Ledogar, 2008). As social workers we search for ways to help families and communities in times of adverse situations. What became clear to us, and what seems to promote positive adaptation despite adversity is outside the scope of individuals, it involves an approach that encourages families and communities to work together to foster an environment that enables people to manage.

\section{Final comment}

Molly found her return to the United States took some considerable adjustment. She missed the people she had shared so much with, and felt a bit displaced and guilty that she had returned to her intact home and life whereas people in Christchurch were still trying to pick up the pieces. Although she had only a month of living through the shakes, when she was back in the United States her body still responded to the slightest movement that felt like an earthquake. She continued to feel vertigo, queasy and off-balance for weeks after her return.

Lynne's home has now been demolished and although not the reason for leaving Christchurch, the earthquakes certainly influenced her decision to accept a position in Australia. Unlike Molly she is able to travel back to New Zealand frequently, and has thus experienced the continued aftershocks and is witness to both the ongoing destruction and the beginning of the rebuild of the city. It is great to see some of what is happening in this regard and to share with family and friends feelings of optimism for the future of Christchurch.

Finally, we both feel privileged to have had the opportunity to offer our professional skills to clients in need attending the Charity Hospital in Christchurch.

\section{References}

Alvord, M., \& Grados, J. (2005). Enhancing resilience in children: A proactive approach. Professional Psychology. Research and Practice, 36, 238-245.

Benveniste, D. (2006). Crisis intervention after major disasters. Carter-Jenkins Website. Retrieved on 2 October, 2012 from http:/ / www.thecjc.org/pdf/benveniste_crisis.pdf.

Fleming, J., \& Ledogar R, J. (2008). Resilience, an evolving concept: A review of literature relevant to Aboriginal research. Pimatisiwin, 6(2), 7-23. PubMed Central Canada. 
Henley, R., Marshall, R., \& Vetter, S. (2011). Integrating mental health services into humanitarian relief responses to social emergencies, disasters, and conflicts: A case study. The Journal of Behavioral Health Services $\mathcal{E}$ Research, $38(1), 132-41$.

Mathbor, G. (2007). Enhancement of community preparedness for natural disasters: The role of social work in building social capital for sustainable disaster relief and management. International Social Work, 50(3), $357-369$.

Melton, G. B., \& Sianko, N. (2010). How can government protect mental health amid a disaster? American Journal of Orthopsychiatry, 80(4), 536-545.

Mukhier, M. (2006). Surviving the Bam earthquake: Psychosocial support helps people to heal. Optimist: Looking beyond the horizon. Available online at: www.optimistmag.org/gb/0014/one.php.

Norris, F. H., Friedman, M. J., \& Watson, P. J. (2002). 60,000 disaster victims speak: Part II. Summary and implications of the disaster mental health research. Psychiatry, 65(3), 240-260.

Patterson, J. (2002). Understanding family resilience. Journal of Clinical Psychology, 58(3), 233-246.

Strongman, L. (2012). Resilience, toughness and damage. Retrieved 12 September, 2012, from http: / / www.australiandesignreview.com/opinion/16811-resilience-toughness-and-damage.

The Press (2012). February 22: Your stories. Retrieved, 17 September, 2012 from http: / / www.stuff.co.nz / the-press / news/christchurch-earthquake.

Radio New Zealand News. Retrieved 12 September, 2012 from http: / / www.radionz.co.nz/ news / canterbury-earthquake.

Yoder, M. (2008). Helping in the wake of disaster: A graduate student's perspective in the aftermath of the VT tragedy. Traumatology, 14, 25 DOI: 10.1177/ 1534765607309941. 